Jurnal Indonesia Sosial Teknologi:p-ISSN: 2723 - 6609

e-ISSN :2745-5254

Vol. 3, No.1 Januari 2022

\title{
PENGOLAHAN BIOMASSA TANDAN KOSONG KELAPA SAWIT SEBAGAI BAHAN BAKAR PEMBANGKIT LISTRIK TENAGA UAP
}

\author{
Dino Erivianto', Ahmad Dani ${ }^{2}$, Haris Gunawan ${ }^{3}$ \\ Program Studi Teknik Elektro, Sekolah Tinggi Teknologi Sinar Husni \\ Email:derivianto@gmail.com, ahmad.kartasasmita@gmail.com,gharis77@yahoo.com
}

\begin{abstract}
Abstrak
Selain menghasilkan produk utama CPO sebanyak 22\% dari proses pengolahan tandan buah segar kelapa sawit, juga menghasilkan produk samping berupa cangkang $6 \%$, fiber $13 \%$ dan tandan kosong kelapa sawit (TKKS) 22\%. Cangkang dan fiber digunakan sebagai bahan bakar boiler di Pabrik Kelapa Sawit (PKS), sedangkan TKKS dibiarkan begitu saja di PKS atau diolah menjadi pupuk. TKKS memiliki potensi sebagai sumber energi terbarukan. Dalam penelitian ini akan menyetarakan TKKS sebagai sumber energi terbarukan dengan cara pengolahan TKKS terlebih dahulu melalui proses kempa untuk menghilangkan kandungan air maupun minyak dan menghasilkan minyak CPO sebesar 2\% dan serabut TKKS sebesar 85\% dengan nilai energi panas sebesar $1.943 \mathrm{kkal} / \mathrm{kg}$. Penelitian juga membandingkan nilai ekonomis dari TKKS, cangkang, fiber dan batubara sebagai bahan bakar PLTU kapasitas 70 ton/jam. Untuk menghasilkan energi listrik sebesar $1 \mathrm{kWh}$ membutuhkan serabut TKKS sebanyak 1,96 kg/jam atau 2,31 kg/jam TKKS dengan biaya bahan bakar sebesar Rp 277, -/kWh, cangkang sebanyak 1,07 kg/jam sebesar $\mathrm{Rp} 749,-/ \mathrm{kWh}$, fiber 1,63 kg/jam sebesar Rp 285,-/kWh dan batubara sebanyak 0,58 kg/jam sebesar Rp 870,-/kWh sedangkan harga jual listrik ke PLN sebesar Rp 870,$/ \mathrm{kWh}$. Keuntungan penjualan listrik terbesar ke PLN diperoleh dari bahan bakar TKKS sebesar Rp 8.895.000,-/jam dan penjualan CPO dari pengolahan TKKS sebesar Rp 4.146.000,-/jam.
\end{abstract}

Kata kunci: kelapa sawit, TKKS, kalori, PLTU, ekonomis

\section{Abstract}

In addition to producing the main product of $C P O$ as much as $22 \%$ from the processing of oil palm fresh fruit bunches, it also produces by-products in the form of $6 \%$ shell, $13 \%$ fiber and 22\% empty oil palm fruit bunches (TKKS). The shell and fiber are used as boiler fuel in the Palm Oil Mill (PKS), while the EFB is left alone in the PKS or processed into fertilizer. TKKS has potential as a renewable energy source. In this study, we will equalize EFB as a renewable energy source by processing EPEFB first through the compression process to remove water and oil content and produce $C P O$ oil by $2 \%$ and EFB fibers by $85 \%$ with a thermal energy value of 1,943 $\mathrm{kcal} / \mathrm{kg}$. The study also compared the economic value of OPEFB, shells, fiber and coal as fuel for PLTU with a capacity of 70 tons/hour. To produce $1 \mathrm{kWh}$ of electrical energy requires $1.96 \mathrm{~kg} / \mathrm{hour}$ EFB fibers or $2.31 \mathrm{~kg} / \mathrm{hour} E F B$ with a fuel cost of Rp. 277, -/kWh, shells of $1.07 \mathrm{~kg} / \mathrm{hour}$ of Rp. 749,- / $\mathrm{kWh}$, fiber 1.63 $\mathrm{kg} / \mathrm{hour}$ at Rp. 285,-/kWh and coal as much as $0.58 \mathrm{~kg} / \mathrm{hour}$ at $\mathrm{Rp} .870,-/ \mathrm{kWh}$ while 
the selling price of electricity to PLN is Rp. 870,-/kWh. The biggest profit from selling electricity to PLN was obtained from TKKS fuel of Rp. 8,895,000,-/hour and CPO sales from TKKS processing of Rp. 4,146,000,-/hour.

Keyword : palm oil, EFB, calories, PLTU, economical

\section{Pendahuluan}

Indonesia merupakan salah satu negara kepulauan terbesar di dunia. Indonesia memiliki sumber daya alam yang tak terhingga (Arsyad, 2020). Keuntungan ini memang karena letaknya yang dilewati garis khatulistiwa sehingga banyak tumbuhan yang bisa hidup di tanah yang cukup subur ini. Salah satu dari banyaknya tumbuhan tersebut adalah kelapa sawit. Kelapa Sawit merupakan tanaman budidaya penghasil utama minyak nabati yaitu Crude Palm Oil (CPO) (Maruli Pardamean, 2012). Saat ini Indonesia merupakan negara penghasil utama minyak nabati kelapa sawit terbesar dunia. Perkebunan kelapa sawit terbesar di Indonesia terdapat di wilayah Sumatera, Kalimantan, Sulawesi, dan Papua. Tahun 2017 luas areal perkebunan kelapa sawit di Indonesia mencapai 14,03 juta ha dengan produksi 37,8 juta ton.(Direktorat Jenderal Perkebunan 2016, 2017)

Meningkatnya perkembangan industri kelapa sawit di Indonesia secara pesat, akan berdampak pada meningkatnya produktivitas pengolahan tandan buah segar (TBS) kelapa sawit dan produk samping (limbah) yang dihasilkan. Limbah padat yang dihasilkan dari pengolahan kelapa sawit berupa cangkang 6\%, fiber $13 \%$ dan tandan kosong kelapa sawit (TKKS) 22\% (Notosudjono, 2012).

TKKS merupakan limbah padat terbesar dari proses pengolahan TBS kelapa sawit dan menjadi masalah terbesar bagi pabrik kelapa sawit (PKS) yang dihadapi selama ini. Umumnya TKKS dibiarkan begitu saja di PKS atau dijadikan pupuk dengan cara pembasahan (damping) ataupun dibakar dalam incinerator, sedangkan untuk limbah cangkang dan fiber dimanfaatkan sebagai bahan bakar boiler di PKS.(Sri Wahyono, 2008)

TKKS diketahui mengandung kadar air yang sangat tinggi sekitar 60\%-65\%, dan mengandung potasium (K) yang mencapai $2,4 \%$, selain itu juga diketahui mengandung klorin $(\mathrm{Cl})$. Efek korosi akan meningkat dengan meningkatnya kandungan $\mathrm{Cl}$, dan unsur potasium dapat berperan dalam pembentukan deposit pada superheater yang dapat mengganggu proses pemindahan panas di tungku boiler (Wijono, 2014).

TKKS digunakan sebagai bahan organik bagi tanaman kelapa sawit secara langsung maupun tidak langsung. Pemanfaatan secara langsung dengan menjadikan TKKS sebagai material penutup budidaya untuk menjaga kelembaban tanah (mulsa) sedangkan secara tidak langsung dengan mengomposkan terlebih dahulu sebelum digunakan sebagai pupuk organik di PKS.(Pahan, 2008)

Pemanfaatan dengan cara tersebut hanya menghasilkan nilai tambah yang terendah didalam proses pengolahan TKKS sehingga diperlukan suatu pengolahan yang tepat untuk mendapatkan nilai tambah yang besar dan menjadi keuntungan bagi perusahaan perkebunan kelapa sawit yaitu kesetaraan biomassa dalam pengolahan limbah kelapa sawit. Kesetaraan biomassa dalam pengembangan energi sebagai energi 
terbarukan (renewable energy) merupakan suatu keharusan dalam uapaya mengatasi defisit energi saat ini.(Febijanto, 2007)

Penelitian ini akan membahas TKKS yang dimanfaatkan sebagai sumber energi terbarukan (renewable energy). Pemanfaatan TKKS sebagai sumber energi terbarukan harus melalui proses pengolahan terlebih dahulu. Proses pengolahan yang dilakukan melalui pengempaan bertujuan untuk menghilangkan kadar air dan minyak yang terkandung didalam TKKS serta menjadi serabut agar mudah terbakar untuk digunakan sebagai bahan bakar boiler pada Pembangkit Listrik Tenaga Uap (PLTU).(Nur, 2014)

Penelitian ini bertujuan untuk mengubah masalah menjadi solusi, bahkan memberikan nilai tambah ekonomi bagi PKS terhadap banyaknya limbah TKKS yang dihadapi selama ini (Tarkono \& Ali, 2016). Kemampuan konversi ini akan membuat persoalan limbah TKKS dapat teratasi dengan tuntas, sedangkan pada aspek ekonomi, limbah TKKS diubah menjadi energi listrik akan menghasilkan keuntungan yang lebih besar bila dibandingkan dengan pemanfaatan TKKS hanya sebagai pupuk. Hingga pada dasarnya semua produk samping kelapa sawit dapat dimanfaatkan sebagai sumber energi baru terbarukan sesuai dengan pemanfaatan yang diinginkan (Zero Emissions) model linier konvensional.(Syukri, 2014)

\section{Metode Penelitian}

Konversi energi tingkat pertama yang berlangsung dalam PLTU adalah konversi energi primer menjadi energi panas. Hal ini dilakukan dalam ruang bakar dari boiler. Energi panas dipindahkan ke dalam air yang ada dalam pipa boiler untuk menghasilkan uap yang dikumpulkan di dalam drum pada boiler. Uap dari drum boiler dialirkan ke turbin uap. Dalam turbin uap, energi uap di konversikan menjadi energi mekanis untuk memutar generator, dan energi mekanis yang berasal dari generator di konversikan menjadi energi listrik.

Penelitian ini menggunakan data PLTU dengan boiler kapasitas 70 ton/jam dengan tekanan uap $36 \mathrm{~kg} / \mathrm{cm} 2$, temperatur $380^{\circ} \mathrm{C}$ dan daya yang dihasilkan $15 \mathrm{MW}$. Adapun spesifikasi boiler sebagai berikut :
a. Merk Boiler
: Takuma
b. Type
: N2200
c. Kapasitas uap (Q)
: $70.000 \mathrm{~kg} / \mathrm{jam}$
d. Temperature uap (Tu) : $380^{\circ} \mathrm{C}$
e. Tekanan uap $(\mathrm{Pu}) \quad: 36 \mathrm{~kg} / \mathrm{cm}^{2}$
f. Temperature air umpan : $105^{\circ} \mathrm{C}$
g. Efisiensi boiler $(\eta): 80 \%$
h. Kalori bahan bakar $\quad: 3.565 \mathrm{kcal} / \mathrm{kg}$ (Cangkang), $2.340 \mathrm{kcal} / \mathrm{kg}$ (fiber), 6.600 $\mathrm{kcal} / \mathrm{kg}$ (batubara) dan $1.943 \mathrm{kcal} / \mathrm{kg}$ (serabut TKKS)

dimana nilai entalphi pada suhu :

Temperatur uap $380^{\circ} \mathrm{C}$ sebesar $757,44 \mathrm{Kcal} / \mathrm{kg}$ dan Temperatur air umpan $105^{\circ} \mathrm{C}$ sebesar $105,16 \mathrm{Kcal} / \mathrm{kg}$ 
Pada umumnya PKS menggunakan metode langsung pada perhitungan boiler $[1,4,6]$. Pada metode langsung tersebut perhitungan efisiensi boiler dapat dievaluasi dengan menggunakan rumus :

$$
\begin{aligned}
\text { Efisiensi }(\eta) & =\frac{\text { Panas Keluar }}{\text { Panas Masuk }} \times 100 \% \\
& =\frac{Q x(h g-h f)}{q \times G C V} \times 100 \%
\end{aligned}
$$

q bahan bakar $=\frac{Q \text { konsumsi }}{\text { kcal bahan bakar }}$

Steam Rate Turbine $=\frac{Q}{P \text { turbin }}=\frac{k g \text { uap }}{k W h}$

Kebutuhan bahan bakar/ton uap $=\frac{q b b}{Q}=\frac{k g \text { bahan bakar }}{\text { ton uap }}$

Banyaknya uap $/ \mathrm{kg} \mathrm{bb}=\frac{Q \text { kg uap }}{\text { bb/ton }}=\frac{\text { ton uap }}{\text { kg bahan bakar }}$

$\mathrm{kWh}=\frac{\text { Steam Rate Turbine }}{\frac{U a p}{\mathrm{kgbb}}}$

Parameter yang dipantau untuk perhitungan efisiensi boiler dengan metode langsung adalah:

a. Jumlah steam boiler yang dihasilkan per jam (Q) dalam kg/jam

b. Jumlah bahan bakar yang digunakan per jam (q) dalam $\mathrm{kg} / \mathrm{jam}$

c. Tekanan kerja dalam $\mathrm{kg} / \mathrm{cm} 2(\mathrm{~g})$

d. Suhu air umpan $\left({ }^{\circ} \mathrm{C}\right)$

e. Jenis bahan bakar dan nilai panas kotor bahan bakar (GCV) dalam kkal/kg bahan bakar

f. hg adalah Entalpi steam jenuh dalam $\mathrm{kkal} / \mathrm{kg}$ steam

g. hf adalah Entalpi air umpan dalam kkal/kg air

\section{Pegolahan Tandan Kosong}

Buah dilepas dari tandannya menggunakan mesin pelepas buah (Threseher Station), buah akan masuk ke konveyor menuju digester untuk diolah menjadi CPO sedangkan tandan kosong jatuh ke konveyor menuju pembuangan. TKKS mengandung minyak yang selama ini merupakan salah satu kehilangan minyak sekitar $2 \%$ yang telah lama diabaikan. TKKS diproses dengan menggunakan mesin pemeras tandan kosong (Empty Fress Bunch). Fungsi mesin pres/kempa (lihat Gambar 4) adalah untuk memisahkan air dan minyak dari tandan kosong yang terikut pada TKKS saat proses perebusan berlangsung. Pemisahan air dan minyak dengan cara mesin berputar dengan satu arah dengan arus listrik 100 ampere sehingga tandan yang masuk dari bagian atas mesin ikut berputar sehingga air, minyak terpisah dari tandan. Minyak dan air masuk ke tangki jus press TKKS melalui pipa di bagian bawah belakang mesin press tandan, sedangkan ampas press tandan terus berputar keluar sampai dibagian depan mesin press dan jatuh ke konveyor bagian bawah mesin press tandan menuju pembuangan limbah. 


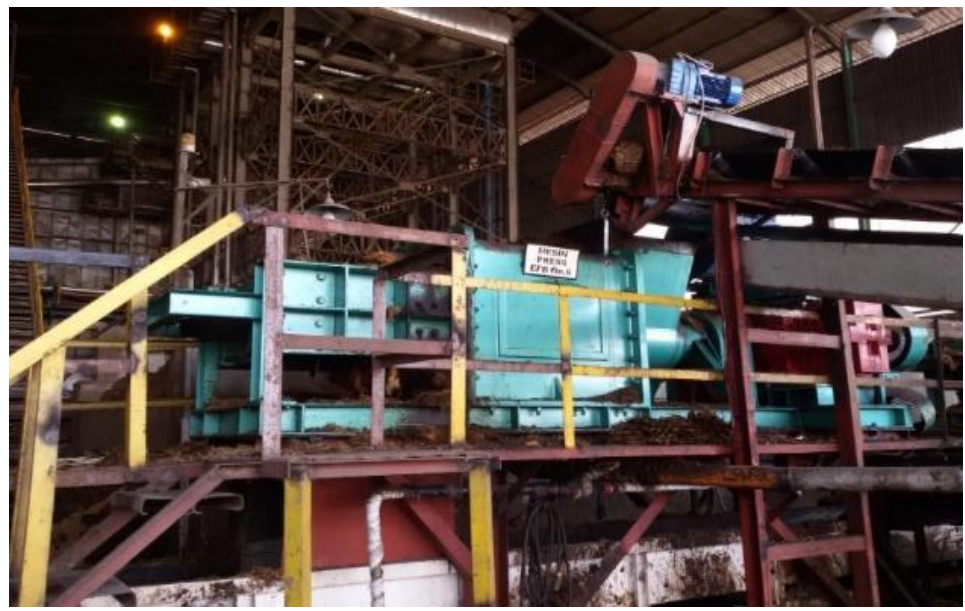

Gambar 4 Mesin Kempa TKKS

Pada proses pengolahan TKKS tersebut menghasilkan serabut TKKS sebesar 85\% $(850 \mathrm{~kg})$ dan limbah sebesar $15 \%(150 \mathrm{~kg})$ dari tiap ton TKKS yang diolah (lihat Gambar 5). Limbah dari proses pengolahan sebesar $15 \%$ memiliki kandungan air dan minyak yang
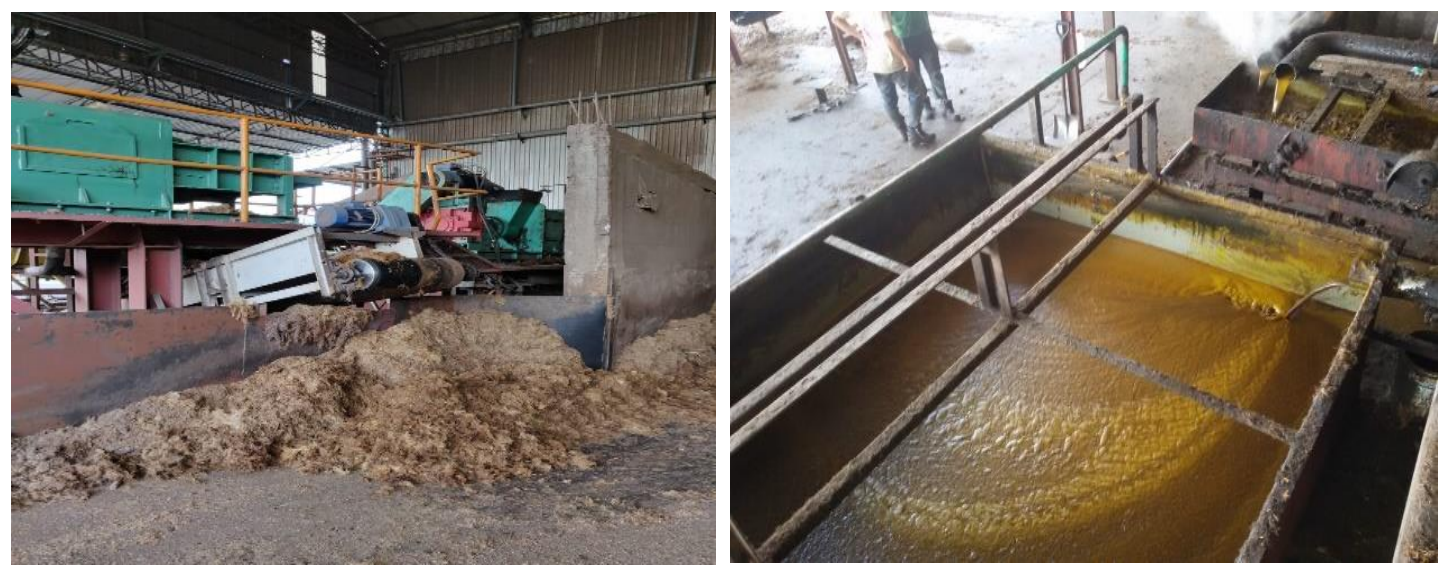

terikut pada TKKS saat perebusan TBS.

(a)

(b)

Gambar 5 (a) Serabut TKKS [4]; (b) CPO dari Pengempaan TKKS

Pada proses pengempaan, kandungan air dan minyak yang terdapat di TKKS akan terpisah dari serabut TKKS. Kandungan air dan minyak akan masuk kedalam limbah TKKS, sehingga perlu dilakukan proses penyaringan dan menyeterilkan minyak dan air agar mendapatkan minyak CPO yang bersih. Proses penyaringan minyak dan air dari limbah TKKS sebesar 15\% tersebut akan menghasilkan CPO 2\%, air 9\% dan solid 4\%.

\section{Hasil dan Pembahasan}

Perhitungan dan Biaya Bahan Bakar PLTU

Rancangan penelitian ini melakukan perbandingan penggunaan bahan bakar 
PLTU dengan mengunakan biomassa dari cangkang (shell), serat (Fiber), batubara dan serabut TKKS. Hasil dari perbandingan banyaknya bahan bakar yang dibutuhkan dan besarnya biaya yang dikeluarkan (diperlihatkan pada Tabel 2), dengan harga beli limbah padat kelapa sawit dan batubara saat ini sebesar :
a. Cangkang (Shell) seharga Rp 700/kg
b. Serabut (Fiber) seharga Rp 175/kg
c. Batubara seharga Rp $1500 / \mathrm{kg}$
d. TKKS seharga Rp 120/kg

Kebutuhan kalor dalam ruang bakar boiler pada PLTU berkapasitas 70 ton/jam dengan tekanan uap $36 \mathrm{~kg} / \mathrm{cm} 2$ dan temperatur $380^{\circ} \mathrm{C}$ serta daya yang dihasilkan $15 \mathrm{MW}$ adalah sebesar $57.074 .500 \mathrm{kcal} / \mathrm{jam}$. Dengan membandingkan nilai kalori yang terkandung didalam masing-masing bahan bakar cangkang sebesar $3.565 \mathrm{kcal} / \mathrm{kg}$, fiber sebesar $2.340 \mathrm{kcal} / \mathrm{kg}$, batubara sebesar $6.600 \mathrm{kcal} / \mathrm{kg}$ dan serabut TKKS sebesar 1.943 $\mathrm{kcal} / \mathrm{kg}$, maka banyaknya bahan bakar yang dibutuhkan pada ruang bakar boiler sebanyak $16.010 \mathrm{~kg}$ cangkang, $24.391 \mathrm{~kg}$ fiber, $8.648 \mathrm{~kg}$ batubara dan $29.375 \mathrm{~kg}$ serabut TKKS atau $34.559 \mathrm{~kg}$ TKKS. Harga beli bahan bakar cangkang sebesar Rp 700,-/kg, fiber Rp 175,-/kg, batubara Rp 1.500,-/kg dan TKKS Rp 120,-/kg sehingga besarnya biaya bahan bakar yang dibutuhkan untuk daya 15 MW pada cangkang sebesar Rp 11.207.000,-/jam, fiber sebesar Rp 4.268.425,-/jam, batubara Rp 12.972.000,-/jam dan TKKS sebesar 4.147.080,-/jam.

Tabel 1 Biaya Dan Kebutuhan Bahan Bakar

Hasil yang didapat dari perhitungan perbandingan biaya bahan bakar cangkang, fiber, batubara dan TKKS sebagaimana yang diperlihatkan pada Tabel 2 didapatkan biaya termurah secara berurut adalah TKKS sebesar Rp 4.147.080,-/jam, fiber sebesar Rp 4.268.425,-/jam, cangkang sebesar Rp 11.207.000,-/jam dan batubara sebesar Rp 12.972.000,-/jam.

\begin{tabular}{|c|c|c|c|c|c|}
\hline \multirow{2}{*}{$\begin{array}{l}\text { Bahan } \\
\text { Bakar }\end{array}$} & \multirow{2}{*}{ Cangkang } & \multirow{2}{*}{ Fiber } & \multirow{2}{*}{ Batubara } & \multicolumn{2}{|l|}{ TKKS } \\
\hline & & & & Serabut TKKS & TKKS \\
\hline $\begin{array}{c}\text { Kcal/Kg Bahan } \\
\text { Bakar }\end{array}$ & 3.565 & 2.340 & 6.600 & 1.943 & \\
\hline Kcal/Jam Boiler & 57.074 .500 & & & & \\
\hline $\begin{array}{c}\text { Kg/Jam Bahan } \\
\text { Bakar }\end{array}$ & 16.010 & 24.391 & 8.648 & 29.375 & 34.559 \\
\hline $\begin{array}{c}\mathrm{Rp} / \mathrm{Kg} \text { Bahan } \\
\text { bakar }\end{array}$ & 700 & 175 & 1.500 & 120 & \\
\hline $\begin{array}{c}\text { Rp/Jam Bahan } \\
\text { Bakar }\end{array}$ & 11.207 .000 & 4.268 .425 & 12.972 .000 & 4.147.080 & \\
\hline
\end{tabular}

Tabel 2 Biaya kWh Bahan Bakar dan Harga Jual listrik 


\begin{tabular}{cccccc}
\hline Harga & $\begin{array}{c}\text { Cangkang } \\
\text { (Shell) }\end{array}$ & $\begin{array}{c}\text { Serat } \\
\text { (Fiber) }\end{array}$ & Batubara & $\begin{array}{c}\text { Serabut } \\
\text { TKKS }\end{array}$ & TKKS \\
\hline Kg BB/kWh & 1,07 & 1,63 & 0,58 & 1,96 & 2,31 \\
\hline Harga BB/Kg & 700 & 175 & 1500 & 120 \\
\hline Rp Per kWh & 749 & 285 & 870 & 277 \\
\hline $\begin{array}{c}\text { Harga Jual Listrik ke PLN } \\
\text { Rp/kWh }\end{array}$ & & & 870 & & \\
\hline Selisih Harga Per kWh & 121 & 585 & 0 & \multicolumn{2}{c}{593} \\
\hline
\end{tabular}

Biaya produksi untuk menghasilkan energi listrik dalam $\mathrm{kWh}$ dari masing-masing bahan bakar yang ditampilkan pada Tabel 3, merupakan lanjutan pada perhitungan atas banyaknya bahan bakar yang dibutuhkan yang ditampilkan pada Tabel 2 serta Steam Rate Turbine dari boiler yang digunakan, sehingga banyaknya bahan bakar yang dibutuhkan pada cangkang, serat, batubara dan serabut TKKS adalah sebesar 1,07 kg cangkang/kWh, $1,63 \mathrm{~kg}$ serat $/ \mathrm{kWh}, 0,58 \mathrm{~kg}$ batubara $/ \mathrm{kWh}$ dan 1,96 serabut TKKS $/ \mathrm{kWh}$ atau 2,31 kg TKKS/kWh. Besarnya biaya bahan bakar yang dikeluarkan berdasarkan harga masingmasing bahan bakar adalah sebesar Rp 749,-/kWh untuk cangkang, Rp 285,-/kWh untuk serat, Rp 870,-/kWh untuk batubara dan Rp 277,-/kWh untuk TKKS.

Energi listrik yang dihasilkan dari PLTU berkapasitas 70 ton/jam tersebut dapat dijual ke PLN, yang mana ketentuan dari PLN harga energi listrik dalam kWh untuk PLTU berbahan bakar biomassa sebesar Rp 870,-/kWh. Sehingga keuntungan yang didapat dari penjualan energi listrik dengan dikurangi biaya bahan bakar yang dikeluarkan masing-masing bahan bakar adalah sebesar Rp 121,-/kWh untuk cangkang, Rp 585,-/kWh untuk fiber dan Rp 593,-/kWh untuk TKKS. Sedangkan pada bahan bakar batubara tidak mendapatkan keuntungan penjualan energi listrik dikarenakan biaya bahan bakar dengan harga jual energi listrik ke PLN sama.

Tabel 3 Selisih Biaya Operasional Dengan Keuntungan Penjualan CPO Dari TKKS

\begin{tabular}{cccc}
\hline \multirow{2}{*}{ Limbah } & TKKS & Serabut TKKS & CPO \\
\cline { 2 - 4 } & $100 \%$ & $85 \%$ & $2 \%$ \\
\hline Kg/Jam & 34.559 & 29.375 & 691 \\
\hline Harga Rp & \multicolumn{3}{c}{120} \\
\hline Harga Rp/Jam & \multicolumn{2}{c}{4.147 .080} & 6.000 \\
\hline
\end{tabular}

Biaya Operasional PLTU/jam 1.080

Pada proses pengempaan, kandungan air dan minyak yang terdapat di TKKS akan terpisah dari serabut TKKS. Proses pengolahan ini menghasilkan serabut TKKS sebesar 
85\% dan limbah TKKS sebesar 15\%. Kandungan air dan minyak akan masuk kedalam limbah TKKS, sehingga perlu dilakukan proses penyaringan dan menyeterilkan minyak dan air agar mendapatkan minyak CPO yang bersih. Proses penyaringan minyak dan air dari limbah TKKS sebesar 15\% tersebut akan menghasilkan CPO 2\%, air 9\% dan solid $4 \%$.

Kebutuhan biomassa dari TKKS untuk bahan bakar PLTU 70 ton/jam sebanyak $34.559 \mathrm{~kg}$, setelah melakukan proses pengempaan menghasilkan serabut TKKS sebanyak 29.375 kg/jam dengan harga beli TKKS sebesar Rp 120,-/kg dan minyak CPO sebanyak 691 kg/jam. Harga minyak CPO saat ini sebesar Rp 6000,-/kg, sehingga total keuntungan dari penjualan CPO sebesar Rp 4.146.000.-/jam. Sedangkan biaya bahan bakar PLTU sebesar Rp 4.147.080,-/jam. Jika membandingkan selisih biaya bahan bakar dengan hasil penjualan CPO sebagaimana ditampilkan pada Tabel 4, maka biaya operasional PLTU tersebut sebesar Rp 1.080,-/jam.

\section{Kajian Ekonomis TKKS}

Kebutuhan akan serabut TKKS pada PLTU untuk menghasilkan daya listrik 15 MW sebanyak $29.375 \mathrm{~kg}$ serabut TKKS/jam maka persedian bahan utama TKKS untuk memenuhi kebutuhan serabut TKKS sebanyak $34.559 \mathrm{~kg}$ TKKS/jam dan CPO yang dihasilkan sebesar 691 kg/jam dengan harga jual Rp 6000,-/kg. Biaya bahan bakar PLTU 15 MW sebesar Rp 277,-/kWh sedangkan harga jual listrik PLTU ke PLN sebesar Rp 870,-/kWh. Dengan membandingkan Tabel 3 dan Tabel 4 diatas, maka keuntungan dalam pemanfaatan TKKS sebagai bahan bakar PLTU melalui proses pengempaan akan memberikan efisiensi dan keuntungan yang sangat besar baik dari penjualan listrik/kWh maupun CPO dari TKKS.

Jika efisiensi dikaji dari penjualan listrik ke PLN, maka keuntungan PKS sebesar Rp 593,-/kWh sehingga total keutungan penjualan energi listrik sebesar Rp 8.895.000,/jam (Rp 593,-/kWh x $15.000 \mathrm{~kW}$ ). Keuntungan tambahan dari penjualan CPO pengolahan TKKS sebesar Rp 4.146.000,-/jam (691 kg/jam x Rp 6000,-/kg). Jadi total keuntungan yang didapat sebesar Rp 13.041.000,-/jam.

Dengan demikian kesetaraan biomassa dalam pengembangan energi sebagai sumber energi terbarukan (renewable energy) pada TKKS merupakan suatu keharusan dalam uapaya mengatasi defisit energi. Mengingat pemanfaatan dan pengolahan TKKS yang tepat akan menghasilkan kesetaraan biomassa yang tidak kalah dengan biomassa lainnya.

\section{Kesimpulan}

TKKS diketahui mengandung kadar air yang sangat tinggi sekitar 60\%-65\%, dan mengandung potasium (K) yang mencapai $2,4 \%$, selain itu juga diketahui mengandung klorin $(\mathrm{Cl})$ yang dapat mengganggu proses pemindahan panas di tungku boiler. Sehingga perlu dilakukan proses pengolahan TKKS sebagai bahan bakar PLTU melalui proses pengempaan terlebih dahulu untuk menghilangkan kandungan air, potasium $(\mathrm{K})$ dan klorin (C). Proses pengolahan TKKS akan menghasilkan minyak CPO sebanyak 691 kg/jam dengan harga jual CPO sebesar Rp 6000,-/kg dan PLTU dengan bahan bakar 
TKKS untuk menghasilkan energi listrik membutuhkan biaya sebesar Rp 277,-/kWh sedangkan harga jual energi listrik ke PLN sebesar Rp 870,-/kWh.

Keuntungan dari penjualan listrik ke PLN sebesar Rp 8.895.000,-/kWh (Rp 593,/kWh x 15.000 kW) dan penjualan CPO sebesar Rp 4.146 .000 (691 kg/jam x Rp 6000,$/ \mathrm{kg}$ ). Sehingga total keuntungan sebesar Rp 13.041.000,-/jam. Dengan mengkaji kesimpulan dari penelitian ini maka PLTU berbahan bakar biomassa dari TKKS layak untuk dibangun. Pembangunannya bisa dengan skema pemilik kebun sawit dan PKS sebagai pengelola PLTU Biomasa maupun skema pemilik kebun dan PKS sebagai penyedia bahan bakar dan investor sebagai pengelola PLTU Biomasa. Pada dasarnya semua produk samping kelapa sawit dapat dimanfaatkan sebagai sumber energi baru terbarukan sesuai dengan pemanfaatan yang diinginkan (Zero Emissions) model linier konvensional. 


\section{Bibliografi}

Arsyad, Nasrullah. (2020). Yurisdiksi Indonesia Di Laut Natuna: Perspektif Hukum Internasional. PETITUM, 8(1 April), 20-36.

Direktorat Jenderal Perkebunan 2016. (2017). Statistik Perkebunan Indonesia 2016-2018: Kelapa sawit. Direktorat Jenderal Perkebunan - Kementerian Pertanian, 55.

Febijanto, Irhan. (2007). Potensi Biomasa Indonesia Sebagai Bahan Bakar Pengganti Energi Fosil. Jurnal Sains Dan Teknologi Indonesia, 9(2).

Maruli Pardamean, Q. I. A. (2012). Sukses Membuka Kebun dan Pabrik Kelapa Sawit. Penebar Swadaya.

Notosudjono, D. (2012). Pemanfaatan Limbah Industri Kelapa Sawit untuk Bahan Bakar. Kepala Biro Perencanaan Ristek. Guru Besar Universitas Pakuan Bogor.

Nur, Syukri Muhammad. (2014). Business Proposal Untuk Pembangkit Listrik dan Produk Bioenergi Berbasis Sawit. PT. Insan Fajar Mandiri Nusantara.

Pahan, Iyung. (2008). Panduan Budidaya Kelapa Sawit untuk Pekebun oke - Google Books.

Sri Wahyono, Firman L. Sahwandan dan Feddy Suryanto. (2008). Tinjauan Terhadap Perkembangan Penelitian Pengolahan Limbah Padat Pabrik Kelapa Sawit.

Syukri, M. Nur. (2014). Karakteristik kelapa Sawit Sebagai Bahan Baku Bioenergi. PT. Insan Fajar Mandiri Nusantara.

Tarkono, Tarkono, \& Ali, Hadi. (2016). Pemanfaatan Limbah Pabrik Kelapa Sawit Sebagai Material Teknik.

Wijono, Agung. (2014). PLTU Biomassa Tandan Kosong Kelapa Sawit Studi Kelayakan Dan Dampak Lingkungan. Simposium Nasional RAPI XIII, (Cl), 111-118. 